\title{
Clinical adverse events in prehospital patients with ST-elevation myocardial infarction transported to a percutaneous coronary intervention centre by basic life support paramedics in a rural region
}

Sylvain Bussières, PhD*; François Bégin, MD*; Pierre-Alexandre Leblanc, MD*; Alain Tanguay, MD, MSc*; Jean-Michel Paradis, $\mathrm{MD}^{\dagger}$; Denise Hébert, $\mathrm{BSc}^{*}$; Richard Fleet, MD, PhD*

\section{CLINICIAN'S CAPSULE}

What is known about the topic?

ST-elevation myocardial infarction (STEMI) patients transported by ambulance are at risk for adverse events. What did this study ask?

What is the impact of transport time on the occurrence of adverse events in the presence of basic life support paramedics?

What did this study find?

Transport time is not associated with a higher risk of adverse events.

Why does this study matter to clinicians?

Largest investigation of adverse events in a Canadian cohort of STEMI patients transported by ambulance.

\section{ABSTRACT}

Objectives: It remains unclear whether ST-elevation myocardial infarction (STEMI) patients transported by ambulance over long distances are at risk for clinical adverse events. We sought to determine the frequency of clinical adverse events in a rural population of STEMI patients and to evaluate the impact of transport time on the occurrence of these events in the presence of basic life support paramedics.

Methods: We performed a health records review of 880 consecutive STEMI patients transported to a percutaneous coronary intervention centre. Patients had continuous electrocardiogram and vital sign monitoring during transport. A classification of clinically important and minor adverse events was established based on a literature search and expert consensus. A multivariate ordinal logistic regression model was used to study the association between transport time $(0-14,15-29, \geq 30$ minutes) and the occurrence of overall clinical adverse events.

Results: Clinically important and minor events were experienced by $18.5 \%$ and $12.2 \%$ of STEMI patients, respectively. The most frequent clinically important events observed were severe hypotension $(6.1 \%)$ and ventricular tachycardia/ventricular fibrillation (5.1\%). Transport time was not associated with a higher risk of experiencing clinical adverse events $(p=0.19)$, but advanced age was associated with adverse events $(p=0.03)$. No deaths were recorded during prehospital transport.

Conclusions: In our study of rural STEMI patients, clinical adverse events were common (30.7\%). However, transport time was not associated with the occurrence of adverse clinical events in these patients.

\section{RÉSUMÉ}

Objectifs: II demeure incertain si les patients ayant subi un infarctus du myocarde avec sus-décalage du segment ST (STEMI : acronyme anglais) et transportés en ambulance sur une longue distance sont susceptibles de subir des événements cliniques indésirables. L'étude visait donc à déterminer la fréquence des événements cliniques indésirables chez des patients ayant subi un STEMI et vivant en milieu rural, et à évaluer l'incidence de la durée du transport effectué par des ambulanciers paramédicaux en soins primaires sur la survenue de ces événements.

Méthode: Nous avons procédé à un examen des dossiers médicaux de 880 patients consécutifs ayant subi un STEMI et transportés dans un centre spécialisé en vue d'une intervention coronarienne percutanée (ICP). Les patients étaient soumis à une surveillance électrocardiographique continue et des signes vitaux durant le transport. Nous avons établi une classification d'événements cliniques indésirables, graves et bénins, fondée sur une recherche documentaire et sur l'avis

From the *UCCSPU, CSSS Alphonse-Desjardins (CHAU Hôtel-Dieu de Lévis), Québec, QC; and the tInstitut universitaire de cardiologie et de pneumologie de Québec (IUCPO), Québec City, QC.

Correspondence to: Dr. Richard Fleet, Chaire de recherche en médecine d'urgence Université Laval-CHAU Hôtel Dieu de Lévis, 143 Rue Wolfe, Lévis, Québec, OC G6V 3Z1, Canada; Email: rfleet@videotron.ca 
consensuel d'experts. Un modèle de régression logistique ordinal multivarié a servi à étudier l'association entre la durée de transport $(0-14,15-29, \geq 30 \mathrm{~min})$ et la survenue, dans l'ensemble, des événements cliniques indésirables.

Résultats: Des événements cliniques indésirables, graves et bénins, ont été enregistrés chez $18,5 \%$ et $12,2 \%$ des patients ayant subi un STEMI, respectivement. Les événements cliniques importants observés les plus fréquents étaient une hypotension grave $(6,1 \%)$ et de tachycardie ventriculaire/ fibrillation ventriculaire $(5,1 \%)$. II n'y avait pas d'association entre la durée de transport et l'augmentation du risque de subir des événements indésirables $(p=0,19)$, mais l'âge avancé était associé à des événements indésirables $(p=0,03)$. Aucun patient $n^{\prime}$ est décédé durant le transport préhospitalier.

Conclusions: Dans notre étude de patients ayant subi un STEMI en milieu rural, les événements cliniques indésirables étaient fréquents $(30,7 \%)$. Toutefois, la durée de transport n'était pas associée à la survenue de ces complications.

Keywords: basic life support, clinical adverse event, myocardial infarction, paramedic, percutaneous coronary intervention (PCI) centre, rural, STEMI

\section{INTRODUCTION}

Approximately 16,000 Canadians die from myocardial infarction every year, and most of these deaths occur outside of the hospital. ${ }^{1}$ Primary percutaneous coronary intervention (PCI) has been shown to be superior to fibrinolytic therapy in ST-elevation myocardial infarction (STEMI) patients when performed in a timely manner. ${ }^{2}$ The use of prehospital electrocardiograms (ECGs) can reduce treatment delays and improve clinical outcomes, ${ }^{3}$ and are recommended for early STEMI diagnosis. ${ }^{4}$ When a STEMI is diagnosed, the current recommendation is to activate the PCI centre while in transport if the PCI can be performed within 90 minutes from first medical contact (American Heart Association [AHA]/American College of Cardiology [ACC]). ${ }^{45}$ While it is known that suspected STEMI patients are at risk for clinical adverse events during transport, it is unclear how often these events occur and which complications are most common. ${ }^{6-9}$ Neither of these studies distinguished between high risk (i.e., clinically important) and low risk (i.e., clinically minor) adverse events. Furthermore, it is unknown whether longer ambulance transport times (which are often the case in rural areas) are associated with the frequency of clinical adverse events. ${ }^{10}$

In the Chaudière-Appalaches and Québec City regions of Canada, an integrated STEMI program has been used to remotely manage suspected STEMI patients since July $2006^{11}$ and consistently achieves the recommended 90-minute interval benchmark for PCI. ${ }^{12}$ With implementation of the STEMI program, paramedics are able to wirelessly transmit a prehospital 12-lead ECG to an emergency department (ED) physician at a regional online medical control centre for interpretation. A confirmed STEMI diagnosis results in the regional online medical control contacting an interventional cardiologist at a PCI facility who then decides whether to activate the cardiac catheterization laboratory and receive the patient. Because this system involves bypassing the nearest ED, potentially unstable STEMI patients are transported by basic life support (BLS) paramedics (equivalent to primary care paramedics [PCPs]) for longer periods of time without nursing or physician supervision in person. In Canada, BLS paramedics have a limited scope of practice that includes cardiopulmonary resuscitation, bag-valve-mask ventilation, semi-automatic defibrillation, and esophageal tracheal airway, or Combitube.

The objectives of this study were 1) to establish a clinically relevant classification of complications in STEMI patients based on evidence from the existing literature; 2) to use this classification to determine the frequency of clinical adverse events among suspected STEMI patients in the Chaudière-Appalaches and Québec City regions; and 3) to assess the association between transport time and the development of clinically important and minor adverse events in this population.

\section{METHODS}

\section{Study design and setting}

We performed a health records review of STEMI patients transported by ambulance to a tertiary cardiology centre. This project was approved by the ethics review board of the Centre intégré de santé et de services sociaux (CISSS) Chaudière-Appalaches and the Québec Heart and Lung Institute-Laval University (IUCPQ-UL), Québec, Canada. 


\section{Population studied}

All remotely diagnosed STEMI patients transported directly by ambulance to the tertiary cardiology centre for PCI (IUCPQ-UL) between January 2007 and June 2016 were included. Patients with dementia, dialysis, or instability who required immediate medical care were excluded.

\section{EMS system description}

According to the Unite de coordination clinique des services préhospitaliers d'urgence (UCCSPU) protocol, the interval time between a first positive ECG and arrival at the PCI centre should be $\leq 60$ minutes, and the mean interval between arrival at the PCI centre and balloon inflation in the cardiac catheterization laboratory is 30 minutes. $^{12}$ A detailed description of the prehospital STEMI remote diagnosis procedure and non-PCI hospital bypass has been published previously. ${ }^{11}$

Automated continuous ECGs were performed every 2 minutes in the Chaudière-Appalaches region using the Ortivus system (Danderyd, Sweden), and BLS paramedics received online medical support allowing for the identification of new STEMI cases during transport and rapid rerouting to PCI centres. In the Québec City area, BLS paramedics had to transmit the ECG to UCCSPU before ambulance departure at the pickup location using the Zoll medical system (Chelmsford, MA) and could not benefit from online medical support. During ambulance transport, paramedics verbally communicated clinical data to the UCCSPU nurse, including age, sex, oxygen saturation, pulse, arterial blood pressure, level of consciousness (LOC) according to the Alert, Voice, Pain, Unresponsive (AVPU) scale, distance to hospital, and any deaths that occurred during prehospital transport. Transport time was defined as the duration between departure from the pickup location and arrival at the hospital. The nurse on duty entered all data in the UCCSPU clinical database after each episode of care. Each nurse received training on data entry. Over the study period, a total of 52 nurses entered clinical data provided by BLS paramedics. Due to missing data in the database, author SB used a data extraction sheet containing the UCCSPU clinical data to validate data or complete the missing information for each patient using information from the ambulance paper reports of patients transported to the PCI centre.

\section{Classification of clinical adverse events}

A literature review was performed to classify adverse events in the prehospital setting as either "clinically important" or "clinically minor" (see the strategy in Appendix A). Based on relevant studies identified through this search, emergency physicians (FB, PAL, $\mathrm{AT}$, and $\mathrm{RF}$ ) and the registered nurse (DH) from the research team used clinical criteria to determine operational definitions of adverse events for systolic blood pressure, heart rate, state of consciousness, and arrhythmias. The experts agreed with these definitions by consensus in a meeting. For every patient who experienced an event, the ECG was reviewed by PAL to determine the specific arrhythmia that occurred. The experts agreed that two or more different clinically minor events should be considered equivalent to one clinically important event.

Comprehensive definitions for prehospital clinical events in STEMI patients were found in one study. ${ }^{9}$ Based on this limited literature, operational definitions were determined and classified as either "clinically important" or "clinically minor" events for hypotension, bradycardia, desaturation, ventricular tachycardia with pulse, altered LOC, and pulse for atrial fibrillation (AFib). This classification scheme is shown in Box 1. We considered AFib pulse with a heart rate $>120 \mathrm{bpm}$, atrioventricular (AV) block (Mobitz 2 and high degree AV block), ventricular tachycardia with pulse, pulseless ventricular tachycardia/ventricular fibrillation, and asystole or pulseless electrical activity (PEA) to be clinically important events.

\section{Statistical analysis}

Patient demographic and clinical characteristics were reported using descriptive statistics. The association between transport time, age, and sex with the occurrence of clinically important events was assessed with a multivariate ordinal logistic regression model. The dependent variable was stratified into three levels according to clinical events defined in Box 1: no event, 1 clinically minor event, or $\geq 1$ clinically important event. Patients who experienced two or more different clinically minor events were placed in the clinically important events group. Clinically minor events occurring to the patients suffering from clinically important events were not reported. Transport time (independent variable) was classified into three levels (0-14 minutes, 
Box 1. Classification and definitions of clinically important events and minor events occurring during prehospital transport of STEMI patients

\begin{tabular}{|c|c|c|}
\hline \multirow[b]{2}{*}{ Event } & \multicolumn{2}{|c|}{ Classification } \\
\hline & Clinically important & Clinically minor \\
\hline Hypotension & Systolic blood pressure $<80 \mathrm{~mm} \mathrm{Hg}$ & $\begin{array}{l}\text { Systolic blood pressure }= \\
80-89 \mathrm{~mm} \mathrm{Hg}\end{array}$ \\
\hline Bradycardia & Heart rate $<40 \mathrm{bpm}$ & Heart rate $=40-49 \mathrm{bpm}$ \\
\hline Desaturation & $\mathrm{O}_{2}<80 \%$ & $\mathrm{O}_{2}=80 \%-89 \%$ \\
\hline AFib & Heart rate $>120 \mathrm{bpm}$ & Heart rate $\leq 120 \mathrm{bpm}$ \\
\hline Altered LOC & with AVPU at painful (P) or unresponsive (U) & with AVPU at verbal (V) \\
\hline Ventricular tachycardia with a pulse & Heart rate $>120 \mathrm{bpm}$ & $\mathrm{X}$ \\
\hline $\begin{array}{l}\text { AV block (Mobitz } 2 \text { and complete AV block } \\
\text { or high degree AV block) }\end{array}$ & $\checkmark$ & $\mathrm{X}$ \\
\hline Ventricular tachycardia/ventricular fibrillation & $\checkmark$ & $\mathrm{X}$ \\
\hline PEA & $\checkmark$ & $\mathrm{X}$ \\
\hline At least two clinically minor events & $\checkmark$ & $\mathrm{X}$ \\
\hline
\end{tabular}

$\mathrm{AFib}=$ Atrial fibrillation; AVPU = Alert, Voice, Pain, Unresponsive; LOC = level of consciousness; PEA = asystole or pulseless electrical activity.

15-29 minutes, $\geq 30$ minutes), representing the length of short, medium, and long transport runs (respectively) in the Chaudière-Appalaches and Québec City regions. Age was classified according to the interquartile ranges. Unadjusted and adjusted odds ratios (OR) were reported for all independent variables. All statistical analyses were conducted using SAS University Edition. ${ }^{13}$

\section{RESULTS}

\section{Patient characteristics}

A total of 1,114 STEMI patients were eligible for transportation to PCI centre between 2007 and 2016 (Figure 1). Eighty-six patients were not included in our cohort because 48 of them were transported to the nearest non-PCI centre for non-medical reasons, and 38 required immediate medical care. The non-medical reasons were a borderline STEMI diagnosis (20 patients), unjustified BLS paramedic decision (9), dementia (5), very old age (4), decision made by the emergency physician (4), late ECG transmission (2), trauma (1), blocked road (2), and palliative care (1). For the remaining 38 patients who experienced a total of 40 clinically important events, the nurse suggested to the BLS paramedic to transport the patient to the nearest non-PCI centre for instability reasons: severe hypotension (systolic blood pressure < $80 \mathrm{~mm} \mathrm{Hg}$; 14), Mobitz 2 and high degree AV block (12), ventricular fibrillation without spontaneous return to alert (8), altered LOC at $\mathrm{P}$ or $\mathrm{U}$ (3), pulmonary

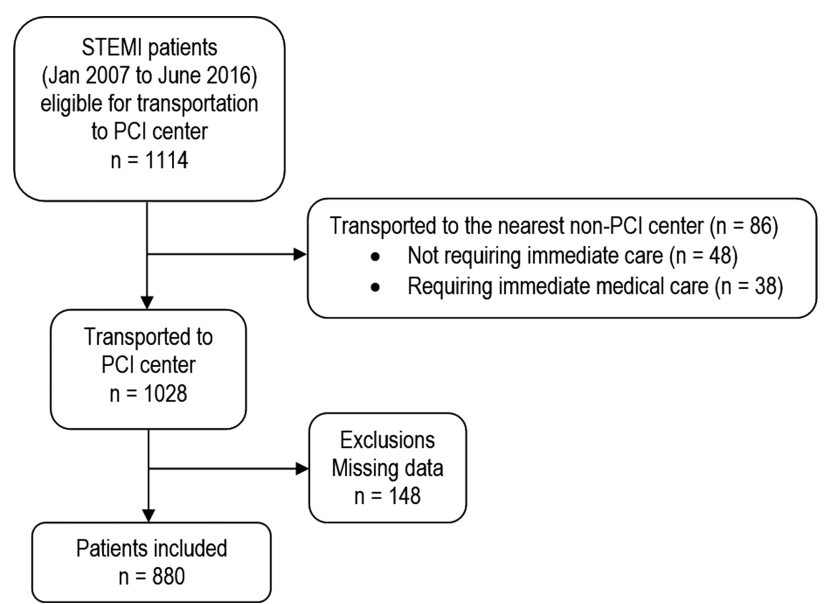

Figure 1. Flow diagram of included patients.

embolism (2), and AFib > 120 (1). Two of these patients suffered from two and three different clinically minor events. As a result, 880 STEMI patients were transported by ambulance to the IUCPQ.

Characteristics of the study population are described in Table 1. STEMI patients were predominantly male $(73.9 \%)$ with a mean age of $65 \pm 13$ years. Most patients were from the rural Chaudière-Appalaches, Portneuf, and Baie-Saint-Paul regions (80\%). Among these patients, $230(21.1 \%)$ were routed directly to the IUCPQ, whereas 650 patients $(73.9 \%)$ were diverted to the IUCPQ after remote interpretation of the prehospital ECG by an ED physician at the regional online medical control centre. Overall, the first positive ECG 


\begin{tabular}{lc|}
\hline Table 1. Population characteristics & \\
\hline Characteristic & Total \\
\hline Patients, $\mathrm{n}$ & 880 \\
Age (mean, SD) & $65(13)$ \\
Male, $\mathrm{n}(\%)$ & $650(73.9)$ \\
Systolic blood pressure (mm Hg, SD) & $122.9(29.6)$ \\
Heart rate (bpm, SD) & $76.5(24.4)$ \\
Saturation (\%, SD) & $96.4(7.9)$ \\
First medical contact to PCl arrival time (min) & \\
0-14, $\mathrm{n}(\%)$ & 336 \\
15-29, $\mathrm{n}$ (\%) & 229 \\
$\geq 30, \mathrm{n}(\%)$ & 276 \\
Median (IQR) & $20(11-36)$ \\
Range & $1-100$ \\
10th percentile & 7 \\
90th percentile & 51 \\
$\quad$ Mean (SD) & $24.5(17.3)$ \\
Number of patients transported $>60$ min (\%) & $25(3)$ \\
\hline Note: Transportation time was available for 841 patients only. & \\
IQR=interquartile range; SD = standard deviation. & \\
\hline
\end{tabular}

to balloon inflation was performed within 90 minutes from their initial positive ECG for 816 patients (97\%), considering that the transportation time was available for 841 patients.

\section{Clinical adverse events}

Of the 880 STEMI patients transported by BLS paramedics, $18.5 \%$ (163/880) experienced 197 clinically important events, and 12.2\% (107/880) experienced 115 clinically minor events during transport (Table 2). Overall, $30.7 \%(270 / 880)$ of patients suffered a clinical adverse event. The most common clinically important events were severe hypotension (systolic blood pressure $<80 \mathrm{~mm} \mathrm{Hg} ; 5.8 \%$ ), ventricular tachycardia/ventricular fibrillation (5.1\%), altered LOC (P or U) (3.3\%), ventricular tachycardia with a pulse $(2.4 \%)$, and $\mathrm{AV}$ block $(2.6 \%)$. The clinically minor events observed most frequently were mild bradycardia (heart rate of 40-49 bpm; 5.3\%), mild hypotension (systolic blood pressure: $80-89 \mathrm{~mm} \mathrm{Hg} ; 4.8 \%$ ), and mild desaturation (80\%-89\%; $0.8 \%)$. All patients suffering from ventricular tachycardia/ventricular fibrillation were successfully resuscitated with semi-automated defibrillation. There were no deaths recorded during prehospital transport. Overall, 40 $(4.5 \%)$ patients suffered greater or equal to two clinically important events, $32(3.6 \%)$ patients experienced two clinically important events, and $7(0.8 \%)$ and $1(0.1 \%)$ suffered from three and four events, respectively.

\begin{tabular}{|c|c|}
\hline & $\begin{array}{l}\text { STEMI patients } \\
\qquad(\mathrm{n}=880)\end{array}$ \\
\hline \multicolumn{2}{|l|}{ All clinical events (important and minor) } \\
\hline Number of patients (\%) & $270(30.7)$ \\
\hline \multicolumn{2}{|l|}{ Clinically important events } \\
\hline Number of patients (\%) & $163(18.5)$ \\
\hline $\begin{array}{l}\text { Severe hypotension } \\
\text { (Systolic blood pressure < } 80 \text { mm Hg) }\end{array}$ & $51(5.8)$ \\
\hline Ventricular tachycardia/ventricular fibrillation & $45(5.1)$ \\
\hline Altered LOC (P or U) & $29(3.3)$ \\
\hline Mobitz 2 and high degree AV block & $23(2.6)$ \\
\hline Ventricular tachycardia with a pulse & $21(2.4)$ \\
\hline Severe bradycardia (Heart rate $<40$ bpm) & $14(1.6)$ \\
\hline Asystole/pulseless electrical activity & $4(0.45)$ \\
\hline Severe desaturation $(<80 \%)$ & $5(0.57)$ \\
\hline AFib $\geq 120$ & $3(0.34)$ \\
\hline Two minor events & 17 \\
\hline Death on arrival at $\mathrm{PCl}$ centre & 0 \\
\hline \multicolumn{2}{|l|}{ Clinically minor events } \\
\hline Number of patients (\%) & $107(12.2)$ \\
\hline Mild bradycardia (heart rate $=40-49$ bpm) & $46(5.3)$ \\
\hline $\begin{array}{l}\text { Mild hypotension } \\
\text { (systolic blood pressure }=80-89 \mathrm{~mm} \mathrm{Hg} \text { ) }\end{array}$ & $42(4.8)$ \\
\hline Mild desaturation (80\%-89\%) & $7(0.8)$ \\
\hline AFib $<120$ & $12(1.48)$ \\
\hline AVPU (V) & $0(0)$ \\
\hline
\end{tabular}

To assess the impact of transportation time, age, and sex on the incidence of clinically important and minor events, a multiple ordinal logistic regression was performed (Table 3). The model initially included a comorbidity variable, which took into account patients suffering from greater or equal to two clinically important events. However, because the number of patients (40) who suffered from two or more clinically important events was too small and resulted in an unstable OR, the variable for comorbidity was removed from the model. Transport time was not associated with clinical events (global $p$-value $=0.19$ ). Ages 74-97 were found to be statistically significant at the 0.05 level when controlling for transportation time and sex $(p=0.03)$.

\section{DISCUSSION}

In this study, we classified clinical adverse events in STEMI patients as either "important" or "minor," 


\begin{tabular}{|c|c|c|c|c|}
\hline \multirow[b]{2}{*}{ Variable } & \multicolumn{2}{|c|}{ Unadjusted analysis } & \multicolumn{2}{|c|}{ Adjusted analysis } \\
\hline & OR $(95 \% \mathrm{Cl})$ & $p$-value & OR $(95 \% \mathrm{Cl})$ & $p$-value \\
\hline \multicolumn{5}{|c|}{ Transportation time } \\
\hline $0-14 \min$ & Reference & & Reference & \\
\hline $15-29 \min$ & $1.07(0.75-1.52)$ & 0.70 & $1.08(0.76-1.55)$ & 0.65 \\
\hline$\geq 30 \mathrm{~min}$ & $0.79(0.56-1.12)$ & 0.18 & $0.78(0.55-1.10)$ & 0.15 \\
\hline Male & $1.12(0.81-1.57)$ & 0.49 & $1.23(0.86-1.75)$ & 0.25 \\
\hline \multicolumn{5}{|l|}{ Age } \\
\hline $22-56$ & Reference & & Reference & \\
\hline $57-64$ & $1.36(0.91-2.04)$ & 0.14 & $1.37(0.91-2.06)$ & 0.14 \\
\hline $65-73$ & $1.36(0.89-2.06)$ & 0.15 & $1.39(0.91-2.13)$ & 0.13 \\
\hline $74-97$ & $1.57(1.05-2.34)$ & 0.028 & $1.66(1.09-2.55)$ & 0.02 \\
\hline
\end{tabular}

based on expert opinion and the published literature. The occurrence of these adverse events was common in our study population with $30.7 \%$ of STEMI patients experiencing at least one event during transport, with more than half of the events being classified as clinically important. Furthermore, we observed that STEMI patients with longer transport times to the PCI centre did not experience more clinical events compared to patients with shorter transport times. However, clinical events were more frequent in the older age group (7497), which could mean that these patients are more at risk from clinical events, regardless of the transportation time. Our findings demonstrate that rural STEMI patients can be safely transported by BLS paramedics over long ambulance runs ( $\geq 30$ minutes).

A prehospital diagnosis of STEMI and direct transport to a PCI centre while bypassing non-PCI hospitals is a well-established strategy for reducing patient contact-to-balloon times. ${ }^{14-16}$ Although most studies have focused on the accuracy of prehospital diagnosis and the duration of transport to PCI, the safety of prolonged transport of rural STEMI patients by BLS paramedics has not been adequately evaluated. To our knowledge, four Canadian studies performed in Ontario have described adverse events occurring during prehospital transport of STEMI patients in urban and suburban settings. A pilot study conducted by Cantor et al. in Ontario concluded that suspected STEMI patients could be safely and effectively transported directly to primary PCI by paramedics without advanced care training. ${ }^{6}$ In that study, 1 of 134 patients developed a rapid atrial flutter during transport that required Advanced Care Paramedic (ACP) skills, 1 patient had ventricular fibrillation, and 5 patients had transient hypotension, for a total of 7 (5\%) clinical adverse events. ${ }^{6}$ In the second study, which was conducted by Ryan et al., 487 STEMI patients were transported by ACPs to a PCI centre or to a non-PCI ED with an interfacility transfer to a PCI laboratory. ${ }^{9}$ The authors reported an overall clinical event rate of $27 \%$, which is higher than the clinically important events rate that we reported (18.5\%). In the third study, STEMI patients were transported by PCPs to either the closest non-PCI centre or to a PCI centre, with an optional ACP rendezvous. Three patients (3\%) experienced a clinically important event (ventricular fibrillation) in the prehospital setting. ${ }^{8}$ In the fourth study, 361 STEMI patients were transported by PCPs to a PCI centre. ${ }^{7}$ In a STEMI bypass guideline that was implemented, PCPs have to request an en route ACPrendezvous to be authorized to transport unstable patients (heart rate $<50$ or $\geq 120$, systolic blood pressure $<80 \mathrm{~mm} \mathrm{Hg}$, or ventilation required). In addition to the 119 unstable patients, 8 stable patients experienced a cardiac arrest under the care of the paramedics, which represented an overall clinical event rate of $35 \%$.

In our cohort, the most common clinically important events were severe hypotension (5.8\%) and ventricular tachycardia/ventricular fibrillation (5.1\%). All patients were successfully resuscitated prior to their arrival at the PCI centre, suggesting that extended transport of mainly rural STEMI patients can be managed by BLS paramedics. It is unlikely that most of the clinical events we observed in our study would have been managed differently by ACPs, with the possible exception of advanced interventions such as external pacemakers for 
patients with Mobitz 2 and complete AV block or high degree AV block $(n=23)$, intravenous fluids for patients with severe hypotension $(\mathrm{n}=51)$, or manual cardioversion for patients with ventricular tachycardia with a pulse $(n=21)$. However, it is unknown whether the benefits of these advanced interventions would offset the potential harm that may occur with delayed transport to the PCI centre. Thus, we believe that STEMI patients benefit more from timely PCI access rather than from a broader range of prehospital interventions.

In Canada, access to primary PCI within recommended time frames is variable; approximately $64 \%$ of patients ages 40 and older are ambulance transported to a PCI facility within 60 minutes. ${ }^{17}$ When a STEMI is diagnosed in the prehospital setting, a bypass of the nearest ED requires potentially unstable STEMI patients to be transported by BLS paramedics for longer periods of time without nursing or physician supervision in person. The results from our study demonstrate that longer transport times for rural patients do not increase the risk of clinical adverse events. Therefore, our study reports that prehospital STEMI triage for primary PCI should be extended to regions that have few or no paramedics with advanced care training, a conclusion that was also drawn by Cantor et al. ${ }^{6}$

There is considerable variability in EMS systems across Canada with respect to training, scope of practice, management, private versus public financing, air medevac capacity, and other factors related to prehospital care. STEMI patients are usually transported to the nearest hospital by paramedics who may not have access to ECG interpretation services in the ambulance. In the province of Québec, the transfer of STEMI patients to a PCI hospital requires an inhospital acute care nurse or physician. ${ }^{18}$ For rural hospitals with limited resources, this may significantly limit the ability of health care providers at the facility to respond to other medical conditions requiring emergency care. ${ }^{4}$ However, this population is more likely to have a longer ischemic time, may be more unstable, and need different interventions. As a consequence, a study should be performed to determine the safety of interfacility transports by PCPs with this subset of patients.

\section{Strengths and limitations}

This study is subject to the known limitations of health records review, which is subject to non-differential information bias. A major limitation was the inability to link to hospital records and patient outcomes. We were unable to evaluate adverse events that may have occurred shortly after hospital arrival. For 38 patients (4.3\%) who experienced a total of 40 clinically important events, the nurse had suggested that BLS paramedics transport the patient to the nearest non-PCI centre for instability reasons, which may have introduced a selection bias. Although the treatments administered by BLS paramedics were captured in the ambulance reports, we were unable to use these data in the analysis due to a large amount of missing values. In addition, continuous monitoring of patient vital signs and ECGs was not available for those patients transported in the Québec City region. There was the potential for misclassification of arrhythmia types due to only one observer reviewing the ECGs. Despite these limitations, this study also has a number of strengths. The clinical data extracted from a medicoadministrative database were validated with ambulance reports to improve data validity. Additionally, this study represents the largest investigation of clinical adverse events in a Canadian cohort of STEMI patients transported by ambulance.

\section{CONCLUSIONS}

Our study demonstrates that transport time is not associated with clinical adverse events in rural STEMI patients who are transported by BLS paramedics. Advanced age was associated with adverse events. Although clinical events were common, there were no deaths recorded during prehospital transport. Further research is needed to determine long-term outcomes in patients who experience clinically important events during ambulance transport. Nevertheless, the results from our study indicate that a prehospital STEMI diagnosis by BLS paramedics followed by triage for primary PCI is safe.

Acknowledgements: We thank Stéphane Turcotte for his assistance with statistical analysis for this study.

Competing interests: None declared.

\section{SUPPLEMENTARY MATERIAL}

To view supplementary material for this article, please visit https://doi.org/10.1017/cem.2018.383 


\section{REFERENCES}

1. Statistics Canada (Health Statistics Division). Mortality, summary list of causes 2009. Ottawa: Minister of Industry; 2012. Available at: http://www.statcan.gc.ca/pub/84f0209x/ 84f0209x2009000-eng.pdf.

2. de Boer SP, Barnes EH, Westerhout CM, et al. High-risk patients with ST-elevation myocardial infarction derive greatest absolute benefit from primary percutaneous coronary intervention: results from the Primary Coronary Angioplasty Trialist versus Thrombolysis (PCAT)-2 Collaboration. Am Heart 7 2011;161(3):500-7e1.

3. Le May MR, Dionne R, Maloney J, et al. The role of paramedics in a primary PCI program for ST-elevation myocardial infarction. Prog Cardiovasc Dis 2010;53 (3):183-7.

4. Welsh RC, Travers A, Huynh T, et al. Canadian Cardiovascular Society Working Group: providing a perspective on the 2007 focused update of the American College of Cardiology and American Heart Association 2004 guidelines for the management of ST-elevation myocardial infarction. Can 7 Cardiol 2009;25(1):25-32.

5. Armstrong PW, Bogaty P, Buller CE, et al. The 2004 ACC/ AHA guidelines: a perspective and adaptation for Canada by the Canadian Cardiovascular Society Working Group. Can 7 Cardiol 2004;20(11):1075-9.

6. Cantor WJ, Hoogeveen P, Robert A, et al. Prehospital diagnosis and triage of ST-elevation myocardial infarction by paramedics without advanced care training. Am Heart 7 2012;164(2):201-6.

7. Kwong JL, Ross G, Turner L, et al. Evaluation of a primary care paramedic STEMI bypass guideline. CFEM 2017; epub, doi:10.1017/cem.2017.415.

8. Ross G, Alsayed T, Turner L, et al. Assessment of the safety and effectiveness of emergency department STEMI bypass by defibrillation-only emergency medical technicians/primary care paramedics. Prehosp Emerg Care 2015;19(2):191-201.

9. Ryan D, Craig AM, Turner L, et al. Clinical events and treatment in prehospital patients with ST-segment elevation myocardial infarction. Prehosp Emerg Care 2013;17(2) :181-6.

10. Bosco C, Oandasan I. Review of family medicine within rural and remote Canada: education, practice, and policy. Mississauga, ON: College of Family Physicians of Canada; 2016.

11. Bussieres S, Tanguay A, Hebert D, et al. Unite de Coordination Clinique des Services Prehospitaliers d'Urgence: a clinical telemedicine platform that improves prehospital and community health care for rural citizens. 7 Telemed Telecare 2017;23(1):188-94.

12. Tanguay A, Dallaire R, Hebert D, et al. Rural patient access to primary percutaneous coronary intervention centers is improved by a novel integrated telemedicine prehospital system. 7 Emerg Med 2015;49(5):657-64.

13. SAS. SAS University Edition. Cary, NC: SAS Institute Inc.; 2017.

14. Camp-Rogers T, Dante S, Kontos MC, et al. The impact of prehospital activation of the cardiac catheterization team on time to treatment for patients presenting with ST-segmentelevation myocardial infarction. Am 7 Emerg Med 2011;29 (9):1117-24.

15. Diercks DB, Kontos MC, Chen AY, et al. Utilization and impact of pre-hospital electrocardiograms for patients with acute ST-segment elevation myocardial infarction: data from the NCDR (National Cardiovascular Data Registry) ACTION (Acute Coronary Treatment and Intervention Outcomes Network) Registry. 7 Am Coll Cardiol 2009;53 (2):161-6

16. Fosbol EL, Granger CB, Jollis JG, et al. The impact of a statewide pre-hospital STEMI strategy to bypass hospitals without percutaneous coronary intervention capability on treatment times. Circulation 2013;127(5):604-12.

17. Patel AB, Tu JV, Waters NM, et al. Access to primary percutaneous coronary intervention for ST-segment elevation myocardial infarction in Canada: a geographic analysis. Open Med 2010;4(1):e13-21.

18. Collège des médecins du Québec. Complémentarité des services d'urgence: prise en charge des patients. Guide d'exercice. Montréal: Collège des médecins du Québec; 1998. 